\title{
RNA interference mediated knockdown of Brugia malayi UDP-Galactopyranose mutase severely affects parasite viability, embryogenesis and in vivo development of infective larvae
}

Sweta Misra ${ }^{1,2}$, Jyoti Gupta ${ }^{1,2}$ and Shailja Misra-Bhattacharya ${ }^{1,2^{*}}$

\begin{abstract}
Background: Galactofuranose is an essential cell surface component present in bacteria, fungi and several nematodes such as Caenorhabditis spp., Brugia spp., Onchocerca spp. and Strongyloides spp. This sugar maintains the integrity of parasite surface and is essential for virulence. UDP-Galactopyranose mutase (bmugm) plays a key role in Galf biosynthesis by catalyzing conversion of UDP-Galactopyranose into UDP-galactofuranose and knockout studies of the gene in Leishmania major, Mycobacterium and Aspergillus fumigatus displayed attenuated virulence while RNA interference study in C. elegans exhibited detrimental effects. Presence of UGM in several prokaryotic and eukaryotic microbial pathogens and its absence in higher eukaryotes renders it an attractive drug target. In the present study, RNA interference studies have been carried out to validate bmugm as an antifilarial drug target.

Methods: RNA interference studies using two different sequences of siRNAs targeting bmugm were carried out. The in vitro gene silencing of adult B. malayi parasites was undertaken to observe the effects on parasites. Infective larvae were also exposed to siRNAs and their in vivo development in jirds was observed.

Results: The in vitro gene silencing induced by siRNA1 and 2 individually as well as together knocked down the bmugm gene expression causing impaired viability of the exposed worms along with extremely reduced motility, abridged microfilarial release and adversely effected embryogenesis. The combinatorial in vitro gene silencing revealed marginally better results than both the siRNAs individually. Thus, infective larvae were treated with siRNA combination which showed downregulation of bmugm mRNA expression resulting into sluggish larval movements and/or death. The siRNA-treated actively motile larvae when inoculated intraperitoneally into jirds demonstrated highly reduced transformation of these larvae into adult worms with detrimental effects on embryogenesis. The effects of gene silencing were long-lasting as the adult worms developed from siRNA-treated larvae showed noticeable knockdown in the target gene expression.
\end{abstract}

Conclusions: The validation studies undertaken here conclude that bmugm is essential for the proper development and survival of the parasite and support its candidature as an antifilarial drug target.

Keywords: UDP-Galactopyranose mutase, Brugia malayi, Lymphatic filariasis, RNAi, Drug target, siRNA, Embryogenesis

\footnotetext{
* Correspondence: shailja_cdri@rediffmail.com;

shailja_bhattacharya@cdri.res.in

${ }^{1}$ Academy of Scientific and Innovative Research (AcSIR), Anusandhan

Bhawan, New Delhi, India

${ }^{2}$ Division of Parasitology CSIR-Central Drug Research Institute, BS 10/1, Sector

10, Jankipuram Extension, Sitapur Road, Lucknow 226031, UP, India
} 


\section{Background}

Lymphatic filariasis (LF) is a vector-borne, painful and disfiguring parasitic disease caused by Wuchereria bancrofti, Brugia malayi and Brugia timori, leading to severe socio-economic consequences. Around 1.23 billion inhabitants in 58 countries are at risk of acquiring infection and therefore urgently require large scale preventive measures [1]. The current standard drugs ivermectin and diethylcarbamazine in combination with albendazole are largely microfilaricidal, moreover they need to be administered in a single dose, annually for several years for proper interruption of the microfilarial transmission. The development of resistance against albendazole and ivermectin has been well established [2], which highlights the urgent need of excavating novel drug targets to discover adulticidal/embryostatic/ microfilaricidal agents. The reverse genetic approach may be of help in this regard and RNA interference (RNAi) provides a valuable modern drug discovery platform for identifying gene(s) playing vital role in parasite metabolism by inhibiting/silencing their expression.

Galactofuranose (Galf), a five member ring form of galactose, is an essential component of cell wall, cell surface glycolipids and glycoproteins. It is widely distributed among several nematodes such as the free-living Caenorhabditis elegans and parasitic Brugia spp., Onchocerca spp. and Strongyloides spp., as well as protozoans and prokaryotes [3]. In mammals, this sugar is exclusively found in hexopyranosyl form $(\mathrm{Gal} p)$. The ubiquitous presence of Gal $f$ in non-mammalian species is remarkable and its expression in many pathogens suggests that it may be an essential element for survival. Absence of Gal $f$ in these organisms often results in morphological abnormalities and an impaired cell wall function. Galfdeficient mutants have been found to be hypersensitive to drugs, exhibited constitutive osmotic stress phenotype or had an attenuated virulence [4]. Thus, apart from maintaining the parasite surface integrity, Galf also appears to be essential for their virulence. Galf-biosynthetic pathways have attracted quite a lot of interest as targets for drug development against microbial infections. The flavoenzyme, UDP-Galactopyranose mutase (UGM) plays a key role in Galf biosynthetic pathway by catalyzing the conversion of UDP-Galactopyranose (UDP-Gal $p$ ) into UDP-galactofuranose (UDP-Galf) [5]. Eukaryotic UGMs share nearly $25-30 \%$ similarity with bacterial UGM and most of the substrate or FAD binding residues have remained conserved [6]. UGM knockouts of Leishmania major and mutants of Aspergillus fumigatus displayed decreased/attenuated virulence $[7,8]$ while $C$. elegans mutants exhibited larval lethality and severe embryonic phenotypic deformities indicative of defective surface coat synthesis [9]. Genome-wide RNAi screens in C. elegans suggested that downregulation of $g l f-1$ gene (an orthologue of $B$. malayi UGM) is detrimental [10-14]. Presence of UGM in several prokaryotic and eukaryotic microbial pathogens and its absence in higher eukaryotes renders it an attractive drug target. An in silico study has also confirmed its relevance as a candidate antifilarial drug target [15]. Thus, in the present study, in vitro and in vivo validation of $B$. malayi UGM as putative antifilarial drug target has been carried out by siRNA mediated gene silencing to understand the biological function of the enzyme in human lymphatic filarial parasite, B. malayi.

\section{Methods}

\section{Customized synthesis of siRNA}

siRNAs (small interfering ribonucleic acids) were custom synthesized by Dharmacon (USA) to target $B$. malayi UGM (bmugm) (NCBI: FJ860969.1). Two sequences of siRNAs labeled with FAM (6-carboxyfluorescein) showing highest specificity ranking were procured in the lyophilized form. Stock solutions $(100 \mu \mathrm{M})$ were prepared and stored at $-80{ }^{\circ} \mathrm{C}$.

Custom synthesized stable scrambled siRNA sequence (negative control) tagged with FAM not bearing any sequence similarities with that of human, rat or mouse and not targeting any gene of $B$. malayi was used to observe off target effects, if any. This scrambled siRNA was prior tested in cell based screening where it showed no effect on cell viability, morphology or proliferation. All the siRNAs were sistable which means that they were modified for nuclease resistance to enhance their stability even in nuclease-rich environments. Sequences of target based and scrambled siRNAs are given in Table 1.

\section{Parasite isolation from infected jirds}

Adult B. malayi parasites were recovered from jirds (Meriones unguiculatus) within 3-5 months of intraperitoneal inoculation of infective larvae (L3) of B. malayi. L3 were recovered from infected Aedes aegypti mosquitoes washed in culture medium repeatedly as described earlier [16]. The worms were retrieved by washing the peritoneal cavity of jird. The recovered worms were washed in culture medium RPMI-1640 containing $2 \mathrm{mM}$ L-glutamine, $25 \mathrm{mM}$ HEPES, $100 \mathrm{U} / \mathrm{ml}$ penicillin, $100 \mathrm{mg} / \mathrm{ml}$ streptomycin and $2.5 \mathrm{mg} / \mathrm{ml}$ amphotericin B.

Table 1 The siRNA sequences used for RNAi studies

\begin{tabular}{llll}
\hline & siRNA & & Sequence (5'-3') \\
\hline $\begin{array}{l}\text { Targeting } \\
\text { bmugm }\end{array}$ & siRNA1 & sense & CAGUAUUAGUGAAGAAGAAUU \\
& anti-sense & UUGUCAUAAUCACUUCUUCUU \\
& siRNA2 & sense & GGAAAUAUGAGGUAUCAAAUU \\
& anti-sense & UUCCUUUAUACUCCAUAGUUU \\
$\begin{array}{l}\text { Non-targeting } \\
\text { scrambled } \\
\text { (negative control) }\end{array}$ & sense & UAGCGACUAAACACAUCAAUU \\
\hline
\end{tabular}


Worms were placed in a 48-well plate keeping 1 worm in $1 \mathrm{ml}$ of culture medium per well and plate was kept at $37{ }^{\circ} \mathrm{C}$ under $5 \% \mathrm{CO}_{2}$ for at least $2 \mathrm{~h}$ to select undamaged, healthy and highly motile worms (male and female) for siRNA treatment.

\section{In vitro siRNA treatment of worms by soaking method}

The healthy male and female adult worms were used for in vitro gene silencing studies by soaking method as described earlier with some modifications [17]. Five male and five female adult worms were placed in Midi GeBaflex tubes with molecular weight cut off (MWCO) of $6-8 \mathrm{kDa}(\mathrm{GeBa}$, Israel) containing $800 \mu \mathrm{l}$ of culture medium fortified with $8 \mathrm{U}$ RNase OUT, $1 \mathrm{mM}$ spermidine and $5 \mu \mathrm{M}$ of target siRNA. The effective concentration of siRNA has been optimized earlier in our lab targeted against other $B$. malayi genes [17, 18]. The tubes with scrambled siRNA and no siRNA instead of target siRNA served as their respective negative and medium controls. FAM labelled stable siRNAs siRNA1 and siRNA2 targeting bmugm mRNA were used alone as well as in combination for analyzing their effect on worms at different time points. Five tubes (medium + worms) were kept in a $250 \mathrm{ml}$ capacity screw capped glass bottle (Schott) containing $200 \mathrm{ml}$ of RPMI medium preheated to $37^{\circ} \mathrm{C}$ and enough care was taken in order to avoid any contamination, stress and damage to the parasites. Of these five tubes, tube $1,2,3,4,5$ contained siRNA1 $(5 \mu \mathrm{M})$, siRNA2 $(5 \mu \mathrm{M})$, siRNA1 + siRNA2 at $2.5 \mu \mathrm{M}$ each, scrambled siRNA (negative control) $(5 \mu \mathrm{M})$ and no siRNA (medium control), respectively. Five such sets of bottles were prepared for retrieving tubes at $24,48,72 \mathrm{~h}$ and the last two for observing the post-silencing effects. Tubes from bottle 1 were retrieved after $24 \mathrm{~h}$ of incubation and adult worms were transferred to fresh medium in separate petridishes. The medium left $(800 \mu \mathrm{l})$ in these five tubes was transferred to separate eppendorfs, centrifuged at $800 \times g$ for $2 \mathrm{~min}$ to pellet microfilariae $(\mathrm{mf})$ released in vitro by female worms. The $\mathrm{mf}$ pellets were suspended in $50 \mu \mathrm{l}$ fresh medium and microscopically examined at different time points during $(24,48,72 \mathrm{~h})$, post-gene silencing $(96,120 \mathrm{~h})$ for enumeration. Ten microliters of $\mathrm{mf}$ suspension was spread into thin smear on a glass slide and stained with Giemsa for observing the phenotypic changes, if any. The images were captured by colour digital camera (Nikon, Tokyo, Japan).

Penetration of siRNA into the treated worm was affirmed by visualization under the fluorescent microscope (FLoid Cell Imaging Station; Life technologies, CA, USA) at $520 \mathrm{~nm}$ emission. However, size/stage-matched parasites were also captured for autofluorescence if any. Two female worms and three male worms from each tube were frozen in Trizol for nucleic acid preparation to measure target gene mRNA expression employing real-time quantitative RT-PCR (qRT-PCR). Further, two male and two female worms were transferred to fresh culture medium at $37{ }^{\circ} \mathrm{C}$ for $30 \mathrm{~min}$ to assess their motility and percentage inhibition in motility, if any. The viability of these worms was evaluated by MTT [3-(4, 5 dimethylthiazol-2-yl)-2, 5 diphenyltetrazolium bromide] reduction assay $[19,20]$. The remaining one female was teased and microscopically examined for intrauterine contents to determine the effect of gene silencing on embryogenesis and other developing progenies. Worms kept in the tubes in two other bottles were also processed in the same way after retrieving parasites at 48 and $72 \mathrm{~h}$ respectively. Worms from the last two bottles were examined for post-silencing effects beyond $72 \mathrm{~h}$ after transferring treated worms to siRNA-free fresh medium and further incubating them for another 24 and $48 \mathrm{~h}$ respectively. These worms were examined for motility, viability and intra uterine contents and remaining parasites were frozen in Trizol for further qRT-PCR. Mf release was also quantified as mentioned earlier. The data stated in the present study are the mean \pm standard deviation (SD) of the three experiments (in each experiment any siRNA type or controls were kept in duplicates for each time point) carried out with the same number of worms under identical conditions.

\section{Effect on motility and viability of $B$. malayi adult worms and microfilariae}

The adult worms (both sexes) from each group of target siRNA soaked, scrambled negative and medium control were analyzed for their motility post-transfer to fresh media. Reduction in motility was analyzed microscopically and \% motility reduction was scored as follows: 5, $1-25 \%$ reduction; $4,26-49 \%$ reduction; $3,50-74 \%$ reduction; 2, 75-99\% reduction; and D (dead), 100\% reduction. MTT utilizes mitochondrial enzyme to reduce yellow dye into blue formazon, which is solubilised in DMSO and read spectrophotometrically in a multiplate reader (Tecan, Infinite M-200, Mannedorf, Switzerland) at $540 \mathrm{~nm}$ indicating viability of worms. Reduction in motility and inhibition in MTT reduction by treated worm in comparison to those of respective controls indicated the effect of gene silencing on B. malayi.

\section{bmugm mRNA expression analysis by qRT-PCR}

The downregulation in the mRNA expression levels of target specific transcript in the treated and control worms was quantified using qRT-PCR. $\beta$-tubulin gene (Bm-tub-1) was used as an endogenous control. The target and housekeeping gene-specific primers were designed (Eurogentec, Seraing, Belgium) for qRT-PCR (Table 2).

The treated and control worms frozen in Trizol at different time points (as mentioned above) were used for 
Table 2 The primers sequences used for real time RT-PCR analysis

\begin{tabular}{lll}
\hline Real time $\mathrm{qPCR}$ primers & Sequence (5'-3') \\
\hline bmugm & sense & CACCTGGTGGATTAAGTCGAACAG \\
anti-sense & AGATGCAAGCCTTTCTCGTTGAAC \\
-tubulin & sense & ACTTGGTGTCCGAATATC \\
& anti-sense & ACTCTTCCTGTTCAATGTAT \\
\hline
\end{tabular}

RNA extraction by Trizol method [21] followed by DNase treatment and cDNA synthesis using Super Script III first strand cDNA synthesis kit (Invitrogen, CA, USA) containing oligo (dT) 20 primers. The cDNA was amplified by qRT-PCR using the real-time PCR primers and SYBER GREEN premix on Roche applied System (Indianapolis, USA). PCR amplification was carried out at $95{ }^{\circ} \mathrm{C}$ for $5 \mathrm{~min}$, followed by 40 cycles of $95{ }^{\circ} \mathrm{C}$ for $20 \mathrm{~s}, 56{ }^{\circ} \mathrm{C}$ for $15 \mathrm{~s}$, and $72{ }^{\circ} \mathrm{C}$ for $30 \mathrm{~s}$ using target specific and endogenous control gene primers. The relative fold change in mRNA expression was determined by comparative $\Delta \mathrm{CT}$ method [22].

To further support the above qRT-PCR findings a separate set of experiments were conducted to check the changes in B. malayi UGM protein (Bm_UGM) levels in treated and untreated worms. Polyclonal antibodies were raised against the protein in BALB/c mice (6-8 week old) and anti-Bm_UGM serum was collected from the blood as mentioned earlier in [23]. The worms (3 males +2 females) from each group after treatment with medium alone and siRNAs (scrambled, siRNA1, 2, 1+2) at different time points as above were homogenized, sonicated in $300 \mu \mathrm{l}$ PBS containing protease inhibitor cocktail (Sigma, St Louis, Missouri, USA), protein content quantified by Bradford method and $20 \mu \mathrm{g}$ of each sample was resolved on 10\% SDS-PAGE for Western blotting using anti-Bm_UGM mouse serum as a primary antibody (1:5000 dilutions). The blot was developed as mentioned earlier [23] and percent relative intensity of bands in comparison to medium control was quantified by using open-source imageJ version 1.47 software $(\mathrm{NIH}$, Bethesda, MD, USA).

\section{In vitro gene silencing in L3 and their in vivo development in jirds}

Brugia malayi L3 were kept in 48 well plate $200 \mathrm{L3/}$ $\mathrm{ml} /$ well in culture medium fortified with $8 \mathrm{U}$ RNase OUT, $1 \mathrm{mM}$ spermidine at $37{ }^{\circ} \mathrm{C}$ in $5 \% \mathrm{CO}_{2}$ [18]. Larvae were soaked in medium containing target siRNA $1+2$ (2 $\mu \mathrm{M})$, scrambled siRNA $(2 \mu \mathrm{M})$ and no siRNA (medium control) in multiple wells for $48 \mathrm{~h}$. Treated as well as control L3 were frozen in Trizol for further quantification of their transcript levels. After washing, the healthy and actively motile larvae from each treated and control groups were inoculated into the peritoneal cavity of 6 week-old susceptible rodent host (male jird) for examining their further in vivo development. Four jirds were inoculated each with $\sim 100 \mathrm{~L} 3 /$ animal recovered from each group of wells. These jirds were euthanized on day 120 post-larval inoculation for observing the development of L3 into sexually mature, fertile adult worms and presence of $\mathrm{mf}$ in peritoneal cavity. The live recovered worms were measured for their length and teased in PBS to detect defects in intrauterine development, if any.

\section{Statistical analysis}

The in vitro and in vivo experiments were repeated three times under similar conditions to minimize the errors, if any. T-test (for two groups), two-way analysis of variance (ANOVA) were used for analyzing the data. Bonferroni method/Newman-Keuls Multiple Comparison Test was used for making individual comparisons using PRISM 5.0 and STATISTICA 7.0 statistical software wherever applicable. Statistical significance between experimental and control groups was evaluated as $P$-values $\leq 0.05$, $\leq 0.01$ and $\leq 0.001$ which were considered to be significant, highly significant, very highly significant and marked as *** and ***, respectively. The probability of each individual comparison was at $100 d f$ (degrees of freedom) for vitro real time data of adult parasites after ANOVA while, in vivo studies (adulticidal, sterilization and real time) the critical probability for $t$-test at $22 d f$ was used.

\section{Results}

\section{Visualization of siRNA uptake by parasites}

There was successful uptake of FAM labelled stable off target siRNA (scrambled), siRNA1, siRNA2 and both siRNA $1+2$ by the parasites on soaking them for $24 \mathrm{~h}$ which was visible equally throughout the body of females (Fig. 1a-d), males (Fig. 2a-d), mf released by siRNA-treated worms (Fig. 3a) and L3 (siRNA1 + 2 soaked) (Fig. 3b) till the end of exposure. The possibility of autofluorescence was ruled out by capturing the size/ stage matched images of unexposed parasites as shown in various figures pertaining to adult female (Fig. 1e), adult male (Fig. 2e), mf (Fig. 3b), L3 (Fig. 3d). Phase contrast images are also included in each figure at right bottom.

\section{Impaired motility and viability of adult $B$. malayi}

Silencing of bmugm mediated through siRNA1, siRNA2 and siRNA $1+2$ caused $50-65 \%$ inhibition in motility of adult female and $60-70 \%$ in male worms within $24 \mathrm{~h}$ of soaking bringing down their viability between 58 and $70 \%$. The motility of worms decreased tremendously at the end of $72 \mathrm{~h}$ (98-99\%) and did not revive on transferring the treated worm to siRNA free fresh medium even 


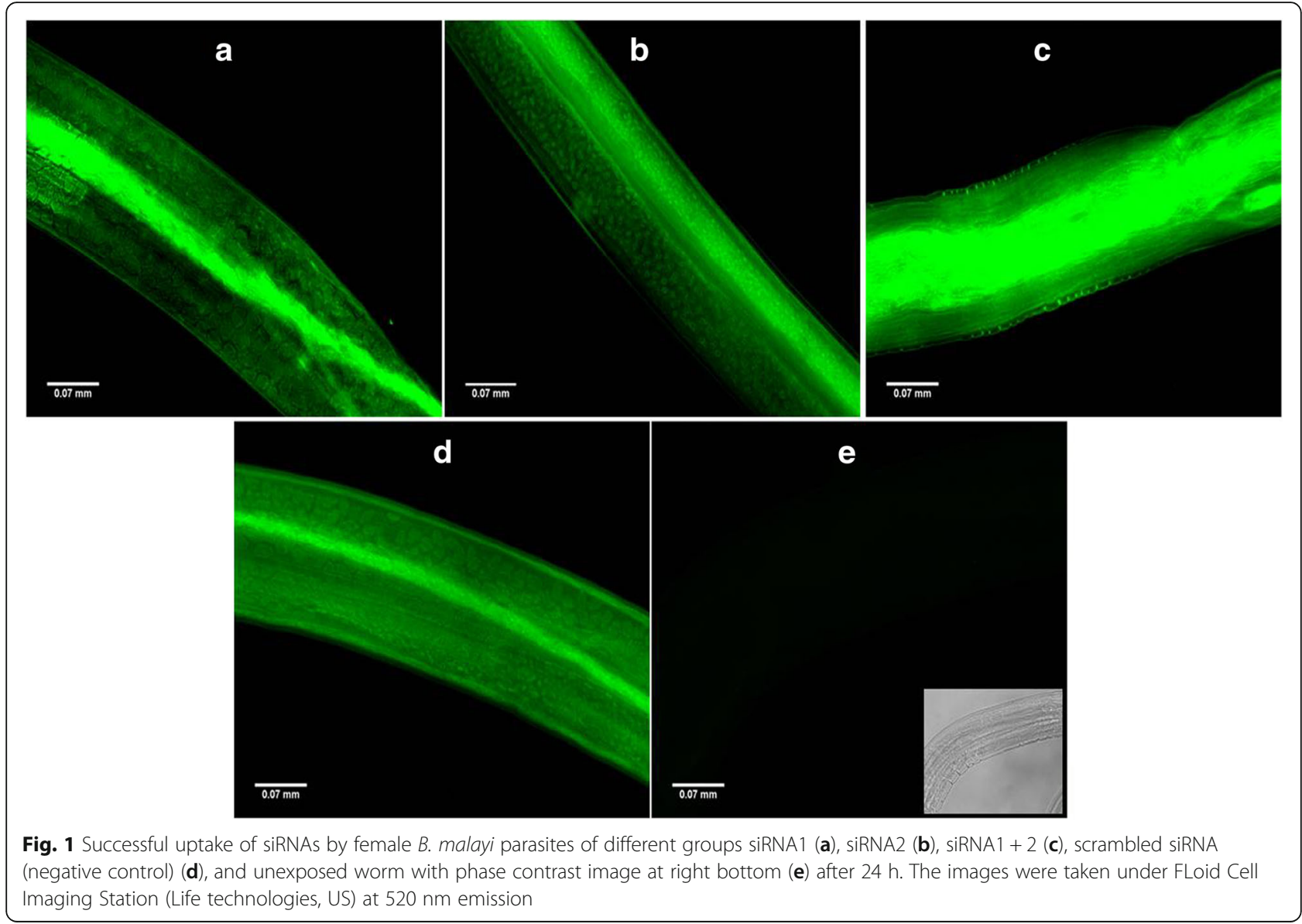

up to $48 \mathrm{~h}$. The worms were almost paralyzed and only their distal end sometimes showed jerky movement on stirring the medium. The viability and motility of treated worms was reduced by 90-98\% between 72 and $120 \mathrm{~h}$ (Tables 3 and 4). These effects were more intense when parasites were soaked in a mixture of two target siRNAs.

Reduced mf release, viability and alteration in phenotype siRNA1, 2 and in combination significantly reduced the release of $\mathrm{mf}$ from female worms in culture. The percent decrease in $\mathrm{mf}$ density was $75 \pm 2.26$ (siRNA1), $73.95 \pm 5.59$ (siRNA2) and $79.45 \pm 2.20 \quad($ siRNA1 +2$)$ within $24 \mathrm{~h}$ which went down further to $\sim 84-86 \%$ at $72 \mathrm{~h}$ and $\sim 90 \%$ after further $48 \mathrm{~h}$ of transfer to siRNAfree medium (Table 5). As expected, targeting of bmugm by two distinct sequences specific siRNAs at any time point proved to be marginally better. No offtarget effects were noticed in presence of scrambled siRNA. Mf released in control cultures were healthy, actively motile (Fig. 4a, b) unlike those targeted specifically. Significant reduction (65-75\%) in the motility of released $\mathrm{mf}$ was observed within $24 \mathrm{~h}$ which was exemplified with increased exposure time ( $>90 \%$ after $48 \mathrm{~h}$ ). Majority of $\mathrm{mf}$ released at $72 \mathrm{~h}$ were dead (Fig. 4c-e and Table 6) with visible phenotypic deformities (Fig. 5a-d) as compared to intact $\mathrm{mf}$ from controls (Fig. 5e).

\section{Impaired embryogenesis in female worm}

An adverse effect was also noticed on intrauterine contents post-bmugm gene silencing in female $B$. malayi. All of the stages including eggs, pretzel, advanced embryonic and microfilarial stages showed degeneration with decrease in their proportions. Female teased at $120 \mathrm{~h}$ contained $66-71 \%$ eggs, $20-23 \%$ embryonic stages, 5-15\% pretzel stages and merely $2-5 \%$ $\mathrm{mf}$ which were much less than in control females. In the specifically targeted worms, percentage of early stages increased significantly with concomitant dwindled counts of advanced developing stages (Fig. 6). The eggs from the two control groups were normal (Fig. 7a, b) as opposed to degenerated eggs in the female worms treated with siRNA1 (Fig. 7c), siRNA2 (Fig. 7d) and siRNA1 +2 (Fig. 7e), these were either granulated and/or shrunken (zoomed view of eggs for showing their condition given on upper left side of each image in Fig. 7). 


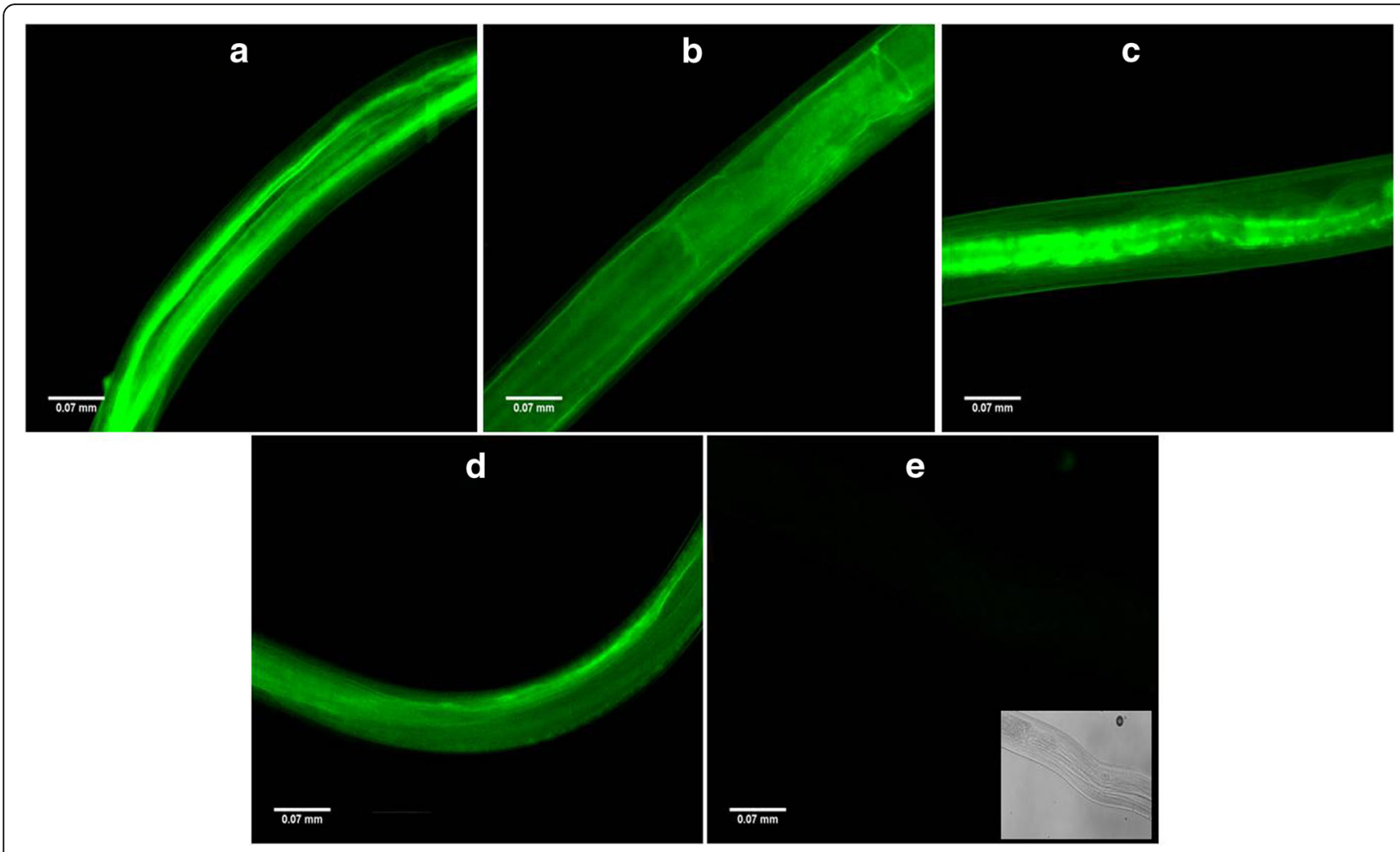

Fig. 2 Successful uptake of siRNAs by male B. malayi parasites of different groups siRNA1 (a), siRNA2 (b), siRNA1 + 2 (c), scrambled siRNA (negative control) (d) and unexposed worm with phase contrast image at right bottom (e) after $24 \mathrm{~h}$ under the fluorescent microscope. The images were taken under FLoid Cell Imaging Station (Life technologies, US) at $520 \mathrm{~nm}$ emission

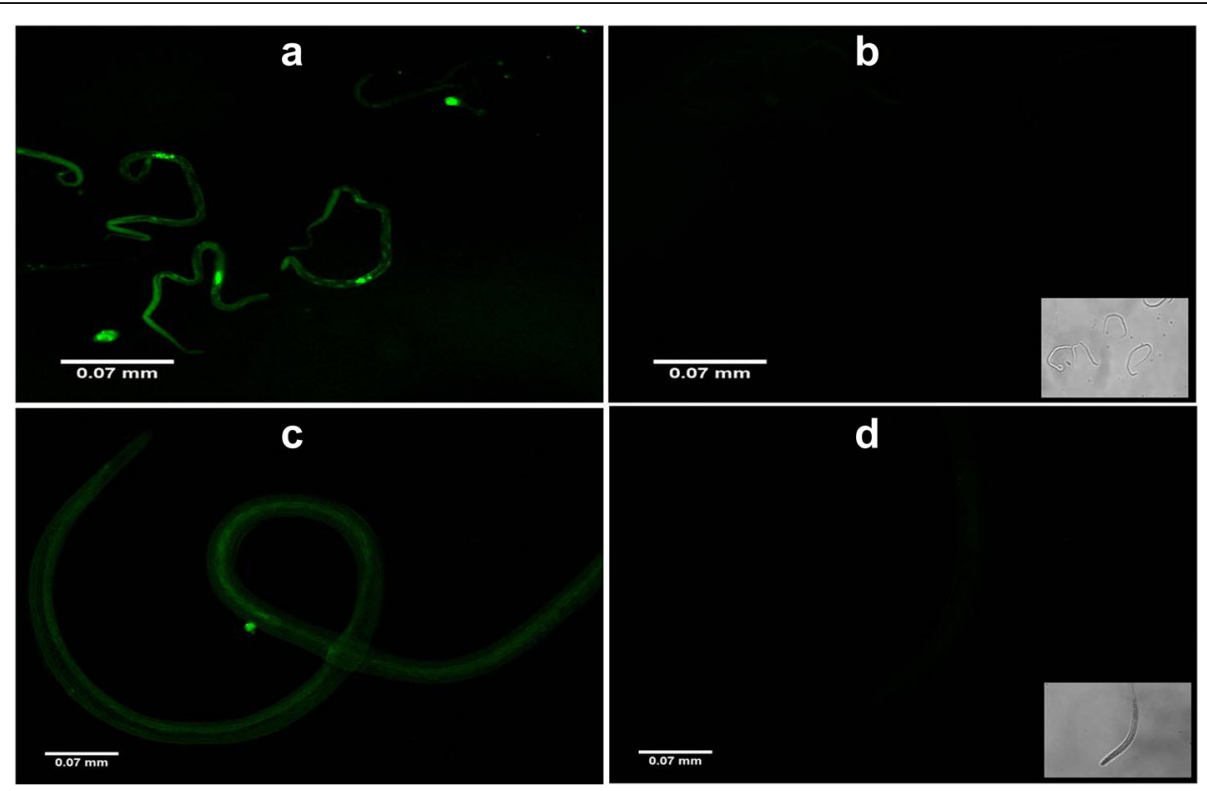

Fig. 3 Successful uptake of siRNAs by B. malayi microfilariae and infective larvae. The images show successful siRNA uptake by B. malayi microfilariae released by siRNA-treated female parasites of different groups (a), unexposed control microfilariae (with phase contrast image at right bottom) (b), siRNA-treated infective larvae (c), and unexposed control infective larvae (with phase contrast image at right bottom) (d) after $24 \mathrm{~h}$ under the fluorescent microscope. The images were taken under FLoid Cell Imaging Station (Life technologies, US) at $520 \mathrm{~nm}$ emission 
Table 3 Effect of bmugm gene silencing on viability of adult B. malayi female parasites assessed by motility scoring and MTT reduction assay

\begin{tabular}{|c|c|c|c|c|c|c|c|c|c|}
\hline \multirow{2}{*}{$\begin{array}{l}\text { Time } \\
\text { (h) }\end{array}$} & \multicolumn{5}{|c|}{ Motility score (female worms) ${ }^{a}$} & \multicolumn{4}{|c|}{$\%$ inhibition in MTT reduction (mean \pm SD) } \\
\hline & $\overline{\mathrm{MC}}$ & SCR & siRNA 1 & siRNA 2 & SiRNA $1+2$ & $\overline{S C R}$ & siRNA 1 & SiRNA 2 & siRNA $1+2$ \\
\hline 24 & $5+$ & $5+$ & $2+$ & $2+$ & $2+$ & $5.2 \pm 0.40$ & $66.1 \pm 5.58^{* *}$ & $57.9 \pm 0.80^{* *}$ & $58.8 \pm 9.89^{* *}$ \\
\hline 48 & $5+$ & $4+$ & $1+$ & $1+$ & $1+$ & $3.7 \pm 3.40$ & $86.9 \pm 1.70^{* * *}$ & $83.4 \pm 3.67^{* * *}$ & $87.6 \pm 1.9^{* * *}$ \\
\hline 72 & $4+$ & $4+$ & $1+$ & $1+$ & $1+$ & $11.1 \pm 1.84$ & $87.3 \pm 9.98^{* * *}$ & $88.6 \pm 1.58^{* * *}$ & $98.1 \pm 2.26^{* * *}$ \\
\hline 96 & $4+$ & $4+$ & $1+$ & $1+$ & $1+$ & $11.3 \pm 3.17$ & $88.7 \pm 2.47^{* * *}$ & $91.5 \pm 1.93^{* * *}$ & $92.2 \pm 2.64^{* * *}$ \\
\hline 120 & $4+$ & $4+$ & $1+$ & $1+$ & $1+$ & $5.3 \pm 0.83$ & $87.8 \pm 3.9^{* * *}$ & $87.4 \pm 2.8^{* * *}$ & $90.1 \pm 3.73^{* * *}$ \\
\hline
\end{tabular}

Abbreviations: MC medium control; MTT (3-(4, 5 dimethylthiazol-2-yl)-2, 5 diphenyltetrazolium bromide); SCR negative control (scrambled siRNA); SD standard deviation

${ }^{* *} P<0.01 ;{ }^{* * *} P<0.001$

${ }^{a} 5,0 \%$ motility reduction; $4,1-25 \%$ reduction; $3,26-49 \%$ reduction; $2,50-74 \%$ reduction; $1,75-99 \%$ reduction; D (death), $100 \%$ reduction

\section{Specific gene silencing led to bmugm transcript knockdown}

The statistical analysis (two way ANOVA followed by pairwise comparisons) showed significant changes among groups $\left(F_{(3,100)}=6761, P<0.001\right)$, at different time points $\left(F_{(4,100)}=1998, P<0.001\right)$. Profound downregulation in the bmugm gene expression was noticeable following in vitro siRNA treatment to adult $B$. malayi. In female worms, mean bmugm transcript level was cut down by approximately 113-fold $\left(t_{(100)}=16.05, P<\right.$ $0.001), 131$-fold $\left(t_{(100)}=18.67, P<0.001\right)$ and 149-fold $\left(t_{(100)}=21.14, P<0.001\right)$ within $24 \mathrm{~h}$ in presence of siRNA1, siRNA2 and siRNA1 +2 , respectively, which reduced further to 445 -fold $\left(t_{(100)}=63.51, P<0.001\right)$, 426fold $\left(t_{(100)}=60.72, P<0.001\right)$ and 523-fold $\left(t_{(100)}=74.54\right.$, $P<0.001$ ) over medium control within $72 \mathrm{~h}$ (Fig. 8a-f). The transcript levels were normalized employing housekeeping gene $\beta$-tubulin (Bm-tub-1). Male worms also showed almost similar results as those of female worms with marginally higher reduction in transcript levels at $24 \mathrm{~h}$ [siRNA1 (204-fold, $t_{(100)}=39.47, P<$ $0.001)$, siRNA2 (205-fold, $\left.t_{(100)}=39.63, \quad P<0.001\right)$, siRNA1 +2 (262-fold, $\left.t_{(100)}=50.75, P<0.001\right]$ and at $72 \mathrm{~h}$ [siRNA1 (410-fold, $\left.t_{(100)}=79.42, \quad P<0.001\right)$, siRNA2 (404-fold, $t_{(100)}=78.33, P<0.001$ ), siRNA1 +2 (505-fold, $\left.\left.t_{(100)}=97.97, P<0.001\right)\right]$ (Fig. 9a-f).
The observations made at the protein levels of Bm_UGM post-treatment substantiated the qRT-PCR data. There was decline at protein levels at $24 \mathrm{~h}$ of treatment which amplified profoundly at 72 hand remained so up to $120 \mathrm{~h}$. The graph has been plotted in terms of band density (Additional file 1: Figure S1).

\section{In vitro gene silencing caused L3 lethality and impaired in vivo development}

The in vitro silencing caused by siRNA $1+2$ was marginally superior to each specific siRNA and therefore this combination was used for soaking L3 to investigate the in vitro effects followed by their further development and establishment in the peritoneal cavity of jirds. Of the L3 larvae soaked in siRNA1 +2 for $24 \mathrm{~h}, 14.0 \%$ were actively motile while majority $(\sim 76.5 \%)$ became sluggish and a few (9.5\%) died. On siRNA treatment for $48 \mathrm{~h}$, only $9.5 \%$ remained active and majority of the larvae $(\sim 51.2 \%)$ died while $39.2 \%$ turned sluggish (Table 7$)$ in contrast to actively motile larvae in controls $(\sim 1-3 \%$ slightly sluggish). There was cut down in the bmugm transcript level of treated L3 (sluggish) by $\sim 178$-fold over that of scrambled siRNA-treated control worms (1.4-fold) as compared to medium control larvae control (Fig. 10a). The actively motile L3 from cultures at the end of $48 \mathrm{~h}$ treatment with target siRNAs, negative

Table 4 Effect of bmugm gene silencing on viability of adult B. malayi male parasites was assessed by motility scoring and MTT reduction assay

\begin{tabular}{|c|c|c|c|c|c|c|c|c|c|}
\hline \multirow{2}{*}{$\begin{array}{l}\text { Time } \\
\text { (h) }\end{array}$} & \multicolumn{5}{|c|}{ Motility score (male worms) ${ }^{a}$} & \multicolumn{4}{|c|}{$\%$ inhibition in MTT reduction (mean \pm SD) } \\
\hline & $M C$ & SCR & siRNA 1 & siRNA 2 & siRNA $1+2$ & NC & siRNA 1 & siRNA 2 & siRNA $1+2$ \\
\hline 24 & $5+$ & $5+$ & $2+$ & $2+$ & $2+$ & $11.6 \pm 1.98$ & $69.1 \pm 9.93^{* *}$ & $69.8 \pm 2.90^{* *}$ & $69.9 \pm 2.13^{* *}$ \\
\hline 48 & $4+$ & $4+$ & $1+$ & $1+$ & $1+$ & $5.9 \pm 2.95$ & $60.7 \pm 10.47^{* *}$ & $77.2 \pm 8.97^{* * *}$ & $84.9 \pm 11.95^{* * *}$ \\
\hline 72 & $4+$ & $4+$ & $1+$ & $1+$ & $1+$ & $7.1 \pm 3.68$ & $80.5 \pm 9.27^{* * *}$ & $85.70 \pm 8.50^{* * *}$ & $92.7 \pm 0.88^{* * *}$ \\
\hline 96 & $3 / 4+$ & $3 / 4+$ & $1+$ & $1+$ & $1+$ & $6.2 \pm 2.35$ & $90.8 \pm 3.60^{* * *}$ & $87.3 \pm 9.60^{* * *}$ & $90.6 \pm 9.53^{* * *}$ \\
\hline 120 & $3 / 4+$ & $3 / 4+$ & $1+$ & $1+$ & $1+$ & $7.9 \pm 4.13$ & $85.2 \pm 2.75^{* * *}$ & $83.5 \pm 9.85^{* * *}$ & $90.9 \pm 1.83^{* * *}$ \\
\hline
\end{tabular}

Abbreviations: NC negative control (scrambled siRNA); $M C$ medium control, $M T T$ (3-(4, 5 dimethylthiazol-2-yl)-2, 5 diphenyltetrazolium bromide); SCR negative control (scrambled siRNA); SD standard deviation ${ }^{*} P<0.01 ;{ }^{* * *} P<0.001$

${ }^{a} 5,0 \%$ motility reduction; $4,1-25 \%$ reduction; $3,26-49 \%$ reduction; $2,50-74 \%$ reduction; $1,75-99 \%$ reduction; D (death), $100 \%$ reduction 
Table 5 Effect of siRNA treatment on microfilaria release by female B. malayi adult parasites

\begin{tabular}{lrlll}
\hline $\begin{array}{l}\text { Time } \\
\text { (h) }\end{array}$ & \multicolumn{4}{l}{ \% inhibition in microfilaria release $($ mean \pm SD) } \\
\cline { 2 - 5 } & SCR & siRNA1 & siRNA2 & siRNA1 + 2 \\
\hline 24 & $4.60 \pm 0.85$ & $75.4 \pm 2.26^{* * *}$ & $73.9 \pm 5.59^{* * *}$ & $79.4 \pm 2.20^{* * *}$ \\
48 & $5.3 \pm 1.25$ & $79.7 \pm 1.84^{* * *}$ & $80.0 \pm 2.97^{* * *}$ & $81.2 \pm 1.96^{* * *}$ \\
72 & $4.3 \pm 0.71$ & $85.3 \pm 1.69^{* * *}$ & $84.7 \pm 2.97^{* * *}$ & $86.3 \pm 1.20^{* * *}$ \\
96 & $3.7 \pm 1.56$ & $88.3 \pm 0.99^{* * *}$ & $87.9 \pm 2.26^{* * *}$ & $88.8 \pm 1.69^{* * *}$ \\
120 & $3.6 \pm 1.56$ & $89.5 \pm 0.71^{* * *}$ & $89.2 \pm 2.26^{* * *}$ & $90.3 \pm 0.99^{* * *}$
\end{tabular}

Abbreviations: MC medium control; SCR negative control (scrambled siRNA); SD standard deviation ***P $<0.001$

control and medium control were inoculated into the peritoneal cavity of 6 week-old male jird (4/group). Jirds euthanized 120 days post-infection revealed drastically reduced $(\sim 75.3 \%)$ adult worm establishment $\left(t\right.$-test: $t_{(22)}=$ 64.09, $P<0.001$ ) (Fig. 10b, c) in addition to sterilization in $\sim 67.3 \%$ (t-test: $\left.t_{(22)}=13.72, P<0.001\right)$ of the established live female worms demonstrating impaired embryogenesis (Fig. 10d).

The adult worms recovered from jirds were also quantified by qRT-PCR for bmugm gene expression which
Table 6 Percentage reduction in motility of microfilariae released by $B$. malayi female adult parasites after in vitro RNA interference was analyzed by scoring their motility

\begin{tabular}{llllll}
\hline \multirow{2}{*}{$\begin{array}{l}\text { Time } \\
\text { (h) }\end{array}$} & \multicolumn{5}{l}{ Reduction in microfilaria motility } \\
\cline { 2 - 6 } & MC & SCR & siRNA1 & siRNA 2 & siRNA1 + 2 \\
\hline 24 & $5+$ & $5+$ & $2+$ & $2+$ & $1+$ \\
48 & $5+$ & $5+$ & $1+$ & $1+$ & $1+$ \\
72 & $5+$ & $5+$ & $1+/ D$ & $1+/ D$ & $1+/ D$ \\
96 & $5+$ & $5+$ & $1+/ D$ & $1+/ D$ & $1+/ D$ \\
120 & $5+$ & $5+$ & $1+/ D$ & $1+/ D$ & $1+/ D$ \\
\hline
\end{tabular}

Abbreviations: MC medium control; SCR negative control (scrambled siRNA) ${ }^{a} 5,0 \%$ motility reduction; $4,1-25 \%$ reduction; $3,26-49 \%$ reduction; $2,50-74 \%$ reduction; $1,75-99 \%$ reduction; D (death), $100 \%$ reduction

revealed 68.4-73.7-fold ( $t$-test: $t_{(22)}=116.1$ (female) and $t_{(22)}=88.51$ (male), $\left.P<0.001\right)$ reduced transcript levels over control parasites (Fig. 10e, f). No significant reduction was noticed in scrambled siRNA-treated group. The worms recovered from jirds inoculated with target siRNA-treated L3 were weak as compared to healthy worms of medium control and negative control; however, there was no noticeable change in the length of adult parasites from those of control groups (Table 8).

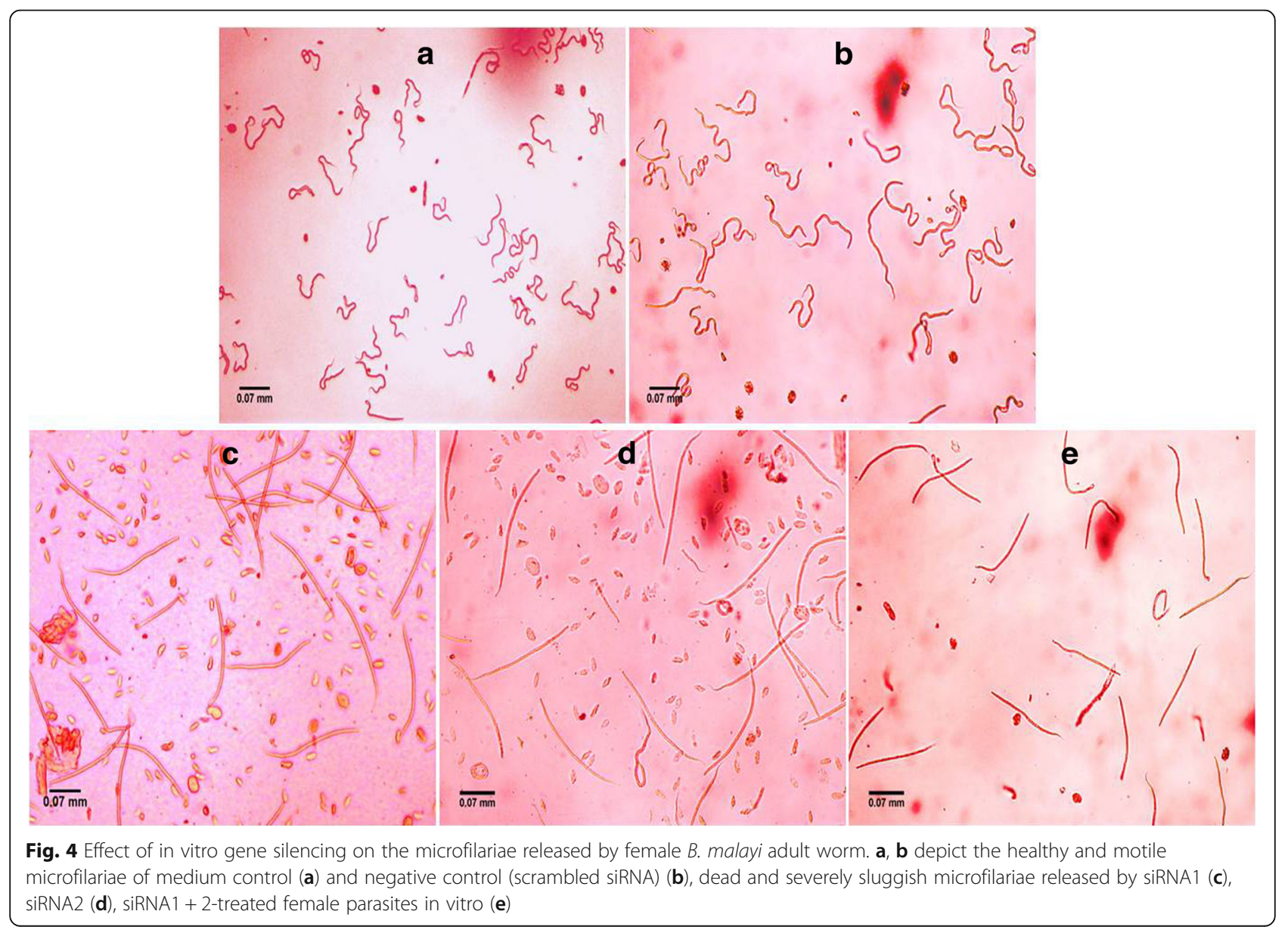




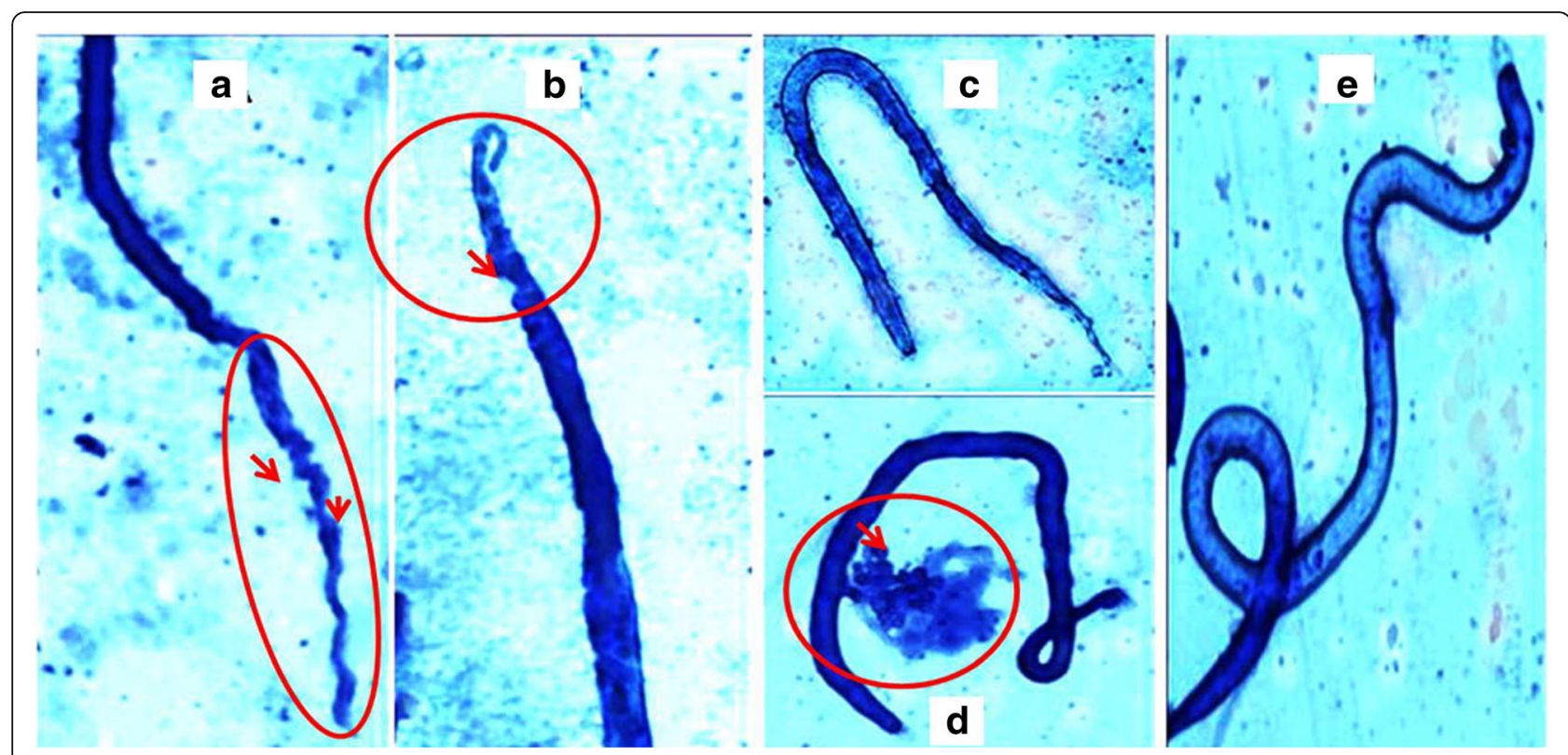

Fig. 5 Phenotypic deformities observed in microfilariae. The microfilariae released by the treated B. malayi adult worms were stained with Giemsa stain for observing the phenotype. The microfilariae recovered from the siRNA-treated groups showed slight deformities (a-d) as encircled and marked (red) in respective images in comparison to the intact microfilariae released in control groups (e)

\section{Discussion}

Mass drug administration is given annually in a single dose for several years to keep microfilarial levels low to interrupt further transmission. The suboptimal response of filaricides together with the emergence of drug resistance advocates discovery of newer chemical moieties and novel drug targets [24-26]. The reverse genetics approach using gene silencing techniques employing small interfering RNAs is being utilized to study gene associated disorders such as cancer, infectious, respiratory and neurodegenerative diseases. RNAi has emerged as a novel and potent tool that regulates post-transcriptional

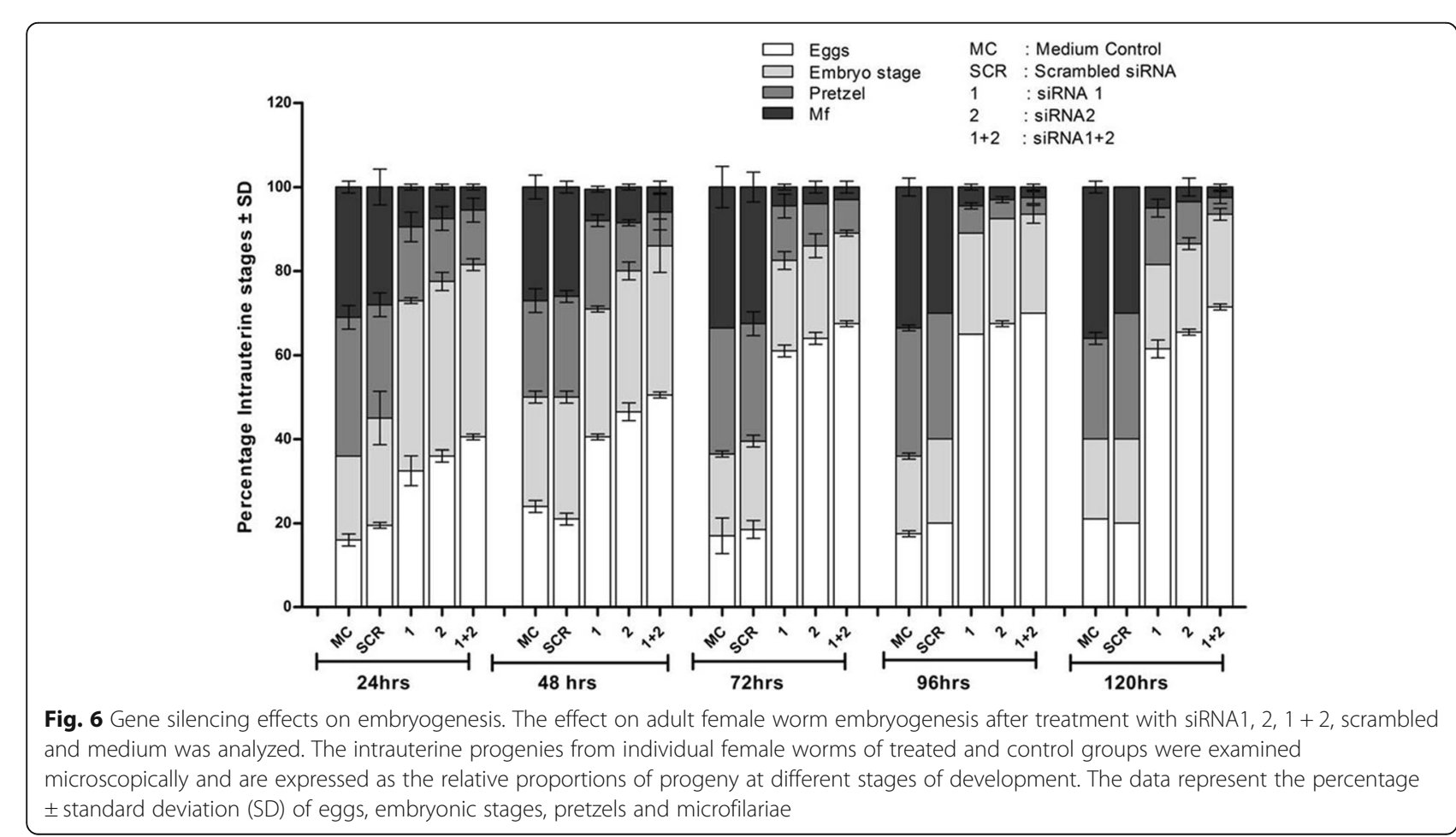




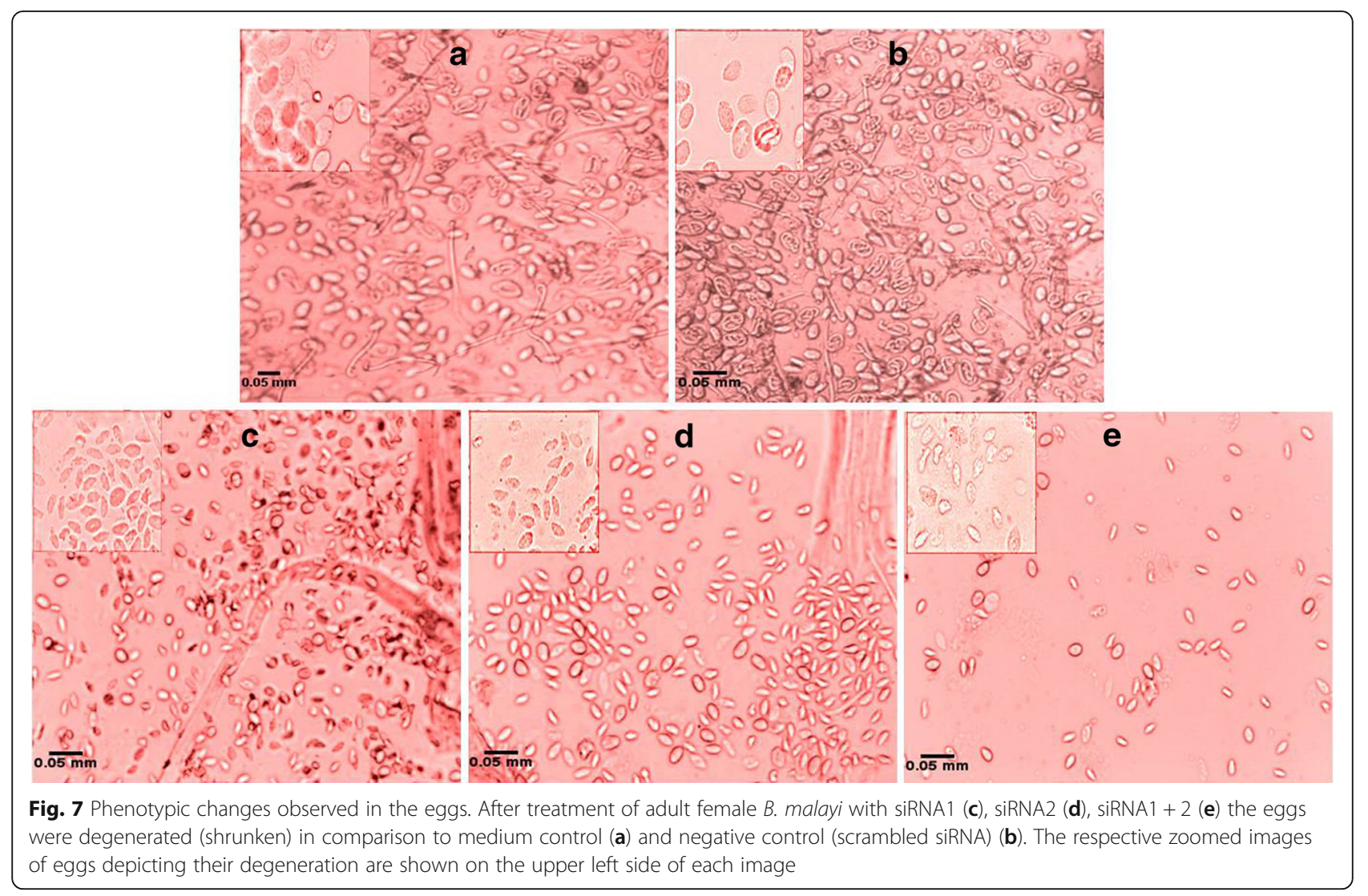

gene expression and helps in functional analysis of target gene/s in several diseases. This technique in C. elegans has greatly helped in excavating the functionality of genes orthologous in B. malayi. A full RNAi screen database is available online showing the phenotypic effects caused by silencing of genes (www.rnai.org). RNAi is being progressively used for predicting potential roles of the genes involved in host-parasite interactions and vital processes essential for survival in many parasitic helminths [27] such as Nippostrongylus brasiliensis [28], Ascaris suum [29, 30], Haemonchus contortus [31-33], Litomosoides sigmodontis [34], Onchocerca volvulus [35, 36], Trichostrongylus colubriformis [37] and Ostertagia ostertagi [38]. Recently, an in vivo gene silencing study has been also undertaken in $B$. malayi mosquito vector $A$. aegypti [39]. Cathepsin-like enzymes, [40], $\beta$-tubulin (Bm-tub-1), RNA polymerase II large subunit (Bmama-1), mf sheath protein (Bm-shp-1) [41] and cysteine proteases [42] have been functionally analyzed by soaking B. malayi worms in siRNA which led to impaired parasite survival and fecundity. Soaking method has been found to be better in parasitic helminths and few essential requirements need to be kept in mind before selecting an appropriate siRNA that should include not only sequence specificity but also most favorable length, concentration, 3' dinucleotide overhangs along with low G/C content [43-46]. Studies have shown that small size siRNAs in low concentrations are more effective and cause less off-target effects than higher concentrations $[47,48]$. We earlier characterized and evaluated the essentiality of few genes of B. malayi such as ATPase RNA helicase,trehalose-6-phosphate phosphatase (TPP), independent phosphoglycerate mutase (iPGM) $[17,18,21]$ by RNAi using single target gene sequence of siRNA; however, improved silencing effects with minimal chances of off target effects could have been obtained if more than one siRNA were used. In the current investigation, two different siRNA sequences targeting same gene were employed anticipating better bmugm gene silencing, a non-B. malayi targeted scrambled siRNA (negative control) was simultaneously used throughout the experiment to observe the off target effects, if any. The siRNAs were picked up by parasite within $24 \mathrm{~h}$ of soaking and were visualized microscopically till the end of exposure period. In vitro gene knockdown using siRNA1 and siRNA2 individually as well as pooled siRNAs $1+2$ of bmugm caused impairment in the viability of exposed worms and tremendously reduced the parasite motility by 98-99\% within $72 \mathrm{~h}$. It was interesting to observe that adverse effects were retained even after $48 \mathrm{~h}$ of replacing the medium with fresh siRNA free medium. In 


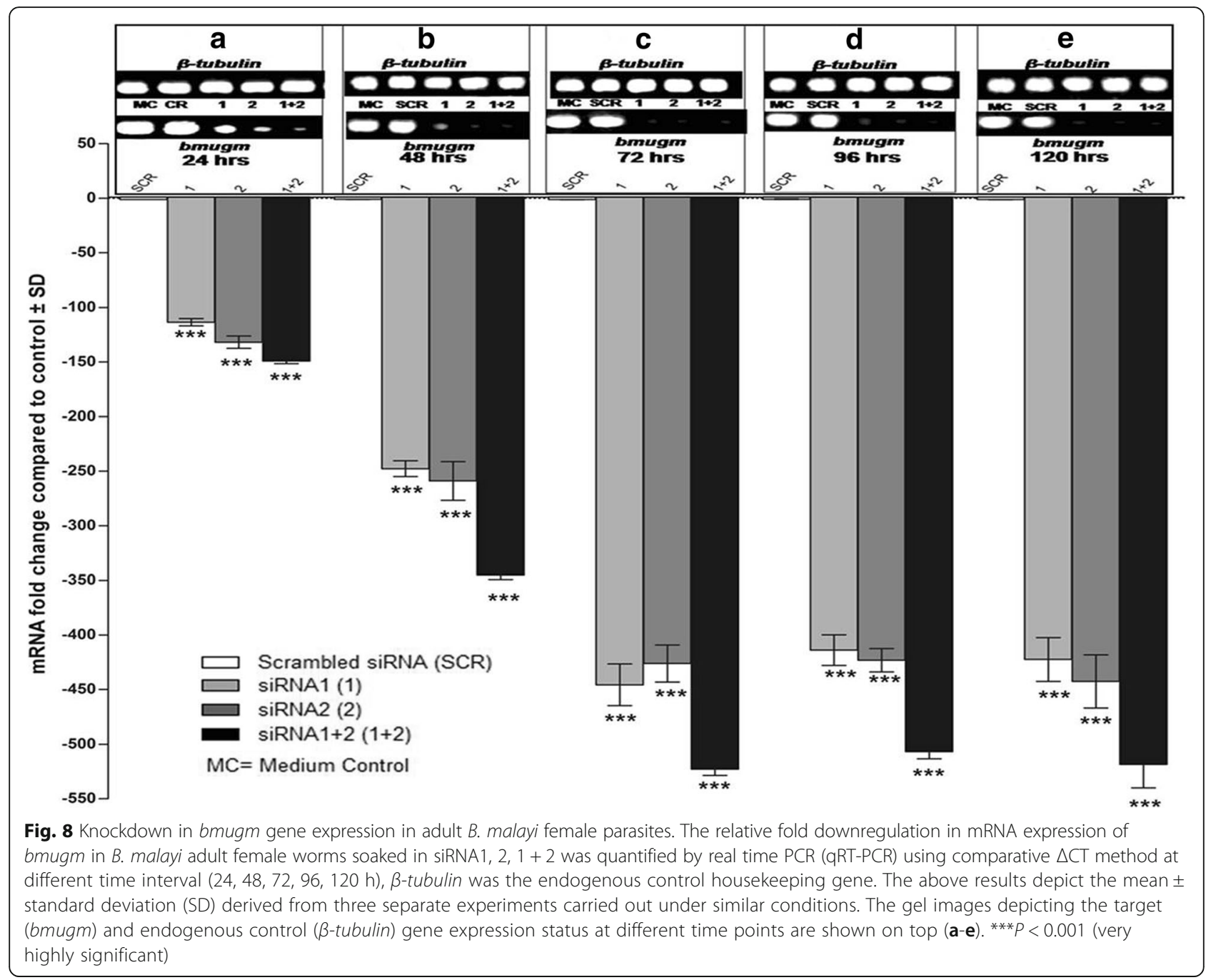

addition to worm motility or viability, the release of $\mathrm{mf}$ by gravid females and their motility was also abridged up to large extent. Gene silencing had tremendous impact on the embryogenesis. More and more early eggs were visible with decrease in advanced developing stages and degeneration of intrauterine stages suggesting phenotypic deformities and development arrest. Real time data revealed knockdown in bmugm expression which amplified further with the exposure duration and persisted even after removal of siRNA. The pooled siRNA effects were $\sim 100$-fold more than in presence of siRNA 1or 2 individually. Both sexes of worms were affected in almost similar fashion. In view of better gene silencing effects of two siRNAs, this combination was exploited in case of infective larvae where deleterious effects were conspicuous making them sluggish, and/or immotile. The treated but actively motile larvae on transfer to healthy susceptible host, jirds demonstrated their highly reduced transformation in to adult worms and recovered female worms had embryostatic effects. Although the size of worms was within limits, they were comparatively much thinner than those recovered from animals receiving untreated larvae. In jirds, L3 takes around 3 months to develop into sexually mature adult parasites; however, the worms developed from siRNA-treated larvae demonstrated $\sim 2.6$ times lower mRNA expression of target gene than detected in L3s soaked for $48 \mathrm{~h}$ in siRNA medium. On the contrary, gene expression in adults established from L3 soaked in scrambled siRNA remained unchanged. These findings suggest that bmugm gene knockdown effect was partly reversible although lasted longer even when the larvae grew and transformed into mature adult parasites in jirds.

In C. elegans, mutation in ugm gene has been shown to culminate in a series of phenotypic defects like traction impairment, superficial blisters, body constrictions, larval lethality, hyper-permeability, drug sensitivity, cuticle fragility and loss, depletion or masking of outer cuticle components $[9,49-53]$ suggesing the essentiality of 


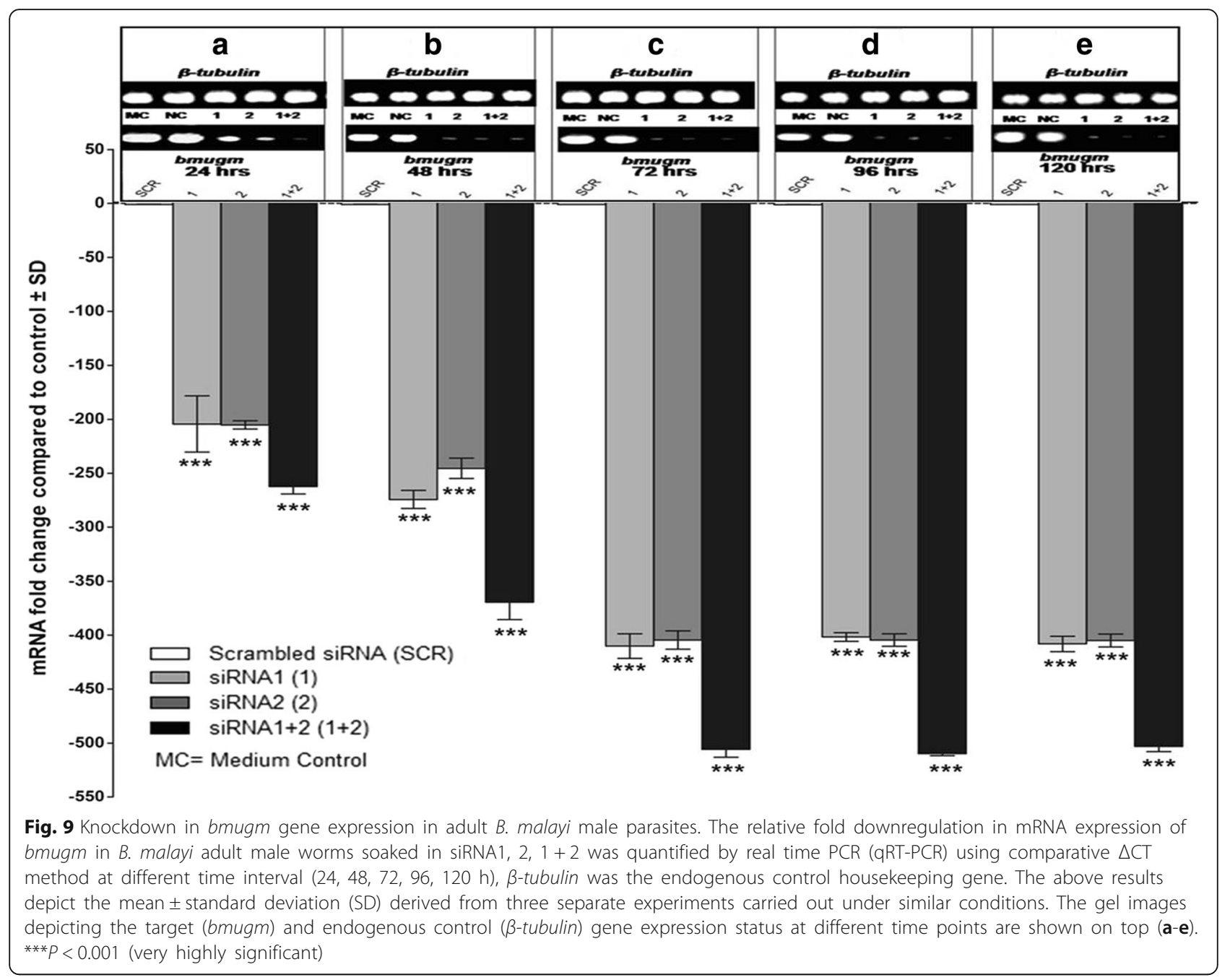

this gene. The current findings demonstrated impaired adult and larval motility, viability and lethality, embryostasis, and other phenotypic alterations as a result of knockdown in bmugm gene expression.

It may therefore be inferred that bmugm is an essential gene in lymphatic filarial parasite, B. malayi which is imperative for their development and survival and thus shows its worth to be picked up as a vital gene target for chemotherapeutic intervention.

\section{Conclusions}

The discovery of alternative chemical moieties with differing mode of action, validated antifilarial drug target and a vaccine to combat filariasis is urgently needed. siRNA mediated gene silencing or compound inhibitor studies are the tools to analyze function of a gene. UGM is widely distributed among nematodes; however, its complete absence in mammals renders it an interesting putative anthelmintic drug target. The drug targets in

Table 7 Effect of siRNA treatment on infective larvae (L3) (mean number \pm standard deviation)

\begin{tabular}{|c|c|c|c|c|c|c|}
\hline \multirow{2}{*}{$\begin{array}{l}\text { L3 } \\
\text { condition }\end{array}$} & \multicolumn{2}{|l|}{$M C$} & \multicolumn{2}{|l|}{ SCR } & \multicolumn{2}{|l|}{ siRNA1 + 2} \\
\hline & $24 \mathrm{~h}$ & $48 \mathrm{~h}$ & $24 \mathrm{~h}$ & $48 \mathrm{~h}$ & $24 \mathrm{~h}$ & $48 h$ \\
\hline Active (\%) & $99.0 \pm 0.71$ & $96.5 \pm 1.41$ & $97.5 \pm 0.27$ & $95.7 \pm 0.47$ & $14.0 \pm 0.71$ & $9.5 \pm 0.64$ \\
\hline Sluggish (\%) & $1.0 \pm 0.78$ & $3.5 \pm 1.42$ & $2.5 \pm 0.97$ & $4.2 \pm 1.68$ & $76.5 \pm 1.97^{* * *}$ & $39.2 \pm 3.94^{* *}$ \\
\hline Dead (\%) & 0 & 0 & 0 & 0 & $9.50 \pm 0.50$ & $51.2 \pm 2.83^{* * *}$ \\
\hline
\end{tabular}

Abbreviations: $M C$ medium control; SCR negative control (scrambled siRNA)

${ }^{* *} P<0.01 ;{ }^{* * *} P<0.001$ 


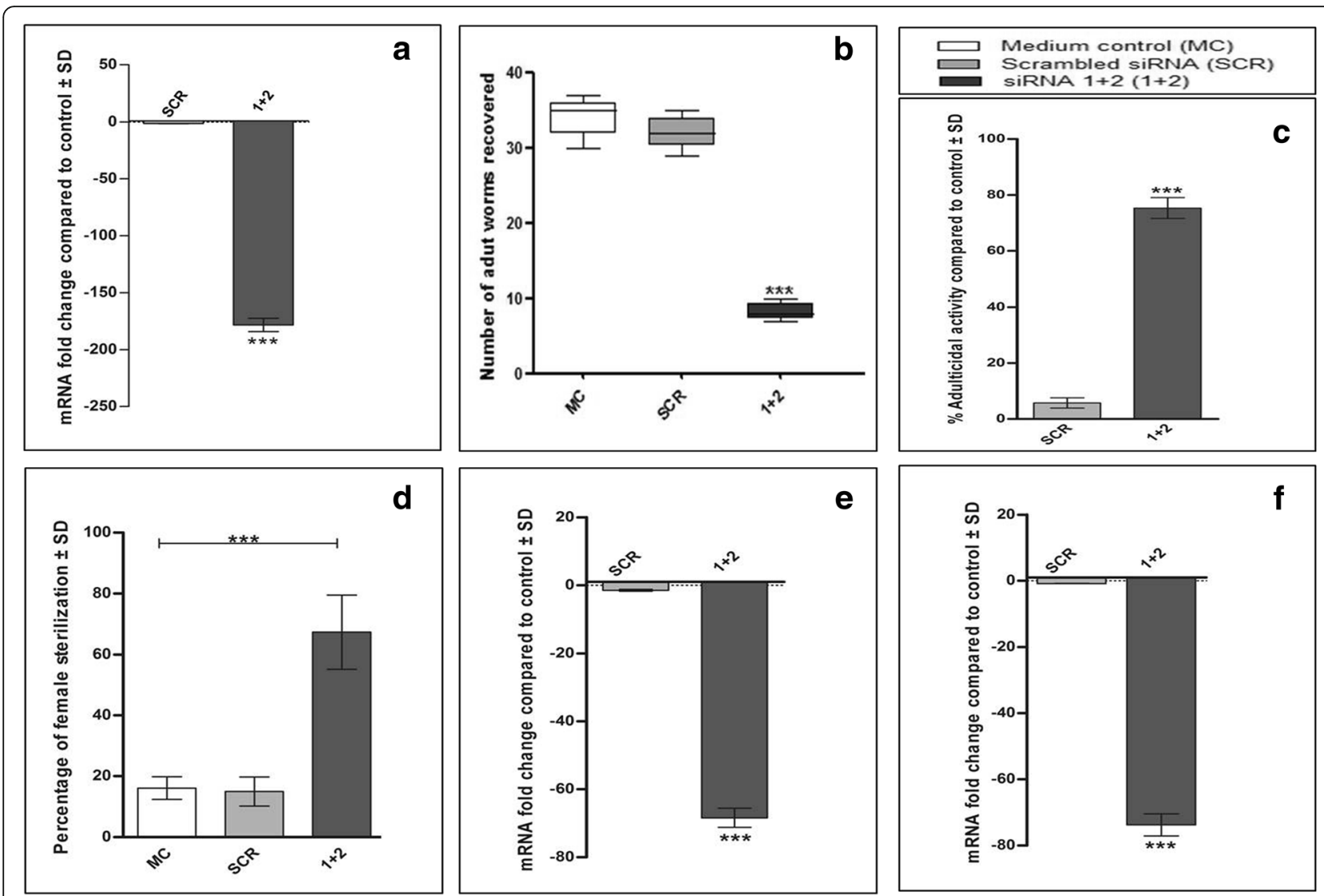

Fig. 10 Effect of in vitro gene silencing on $L 3$ and their in vivo development in jirds. In vitro treatment of $L 3$ with siRNA1 +2 resulted into reduction in bmugm gene expression and impaired their in vivo development in jirds. a siRNA treatment of L3 resulted in a significant knockdown in bmugm gene expression after $48 \mathrm{~h}$ of incubation. $\mathbf{b}, \mathbf{c}$ L3 incubated with siRNA $1+2$, negative siRNA and in medium for $48 \mathrm{~h}$ were inoculated in the peritoneal cavity of jirds followed by euthanization on 120-day post-inoculation for recovery of adult worms which revealed significantly reduced in vivo adult worms establishment in siRNA1 + 2 group. $\mathbf{d}$ Significant number of female worms recovered from siRNA-treated group displayed impaired embryogenesis. Percent of sterile females was calculated with respect to total female worms recovered. The fold downregulation in target gene expression in vivo recovered females (e) and males (f) was also quantified by Real time PCR. ${ }^{* *} P<0.001$ (very highly significant)

helminths including filariids are almost non-existent. RNAi experiments using two B. malayi ugm-specific siRNAs in combination carried out in current study revealed the essentiality of bmugm in filarial metabolism. The studies were undertaken both in vitro and in vivo which caused profound adverse effects on parasite survival and viability correlating with profound knockdown

Table 8 Effect of silencing on the length (mean \pm standard deviation) of male and female worms recovered from jirds infected with in vitro siRNA-treated (bmugm specific, negative) and untreated L3

\begin{tabular}{lcc}
\hline Groups & Worm length $(\mathrm{cm})$ & \\
\cline { 2 - 3 } & Female worms & Male worms \\
\hline Medium control & $3.7 \pm 0.09$ & $1.75 \pm 0.06$ \\
Scrambled siRNA & $3.7 \pm 0.08$ & $1.72 \pm 0.1$ \\
siRNA1 +2 & $3.5 \pm 0.07^{* *}$ & $1.58 \pm 0.05^{*}$ \\
\hline${ }^{* P}<0.05 ;{ }^{* * P}<0.01$ &
\end{tabular}

\section{Additional file}

Additional file 1: Figure S1. The graph bars depict percent relative intensity of bands on western blot in comparison to medium control at different time points of exposure $(24,48,72$ h) and after exposure (96, $120 \mathrm{~h}$ ) as quantified by image version 1.47 software and the blot bands 
have been shown below each corresponding bar. Considering the medium control intensity to be $100 \%$ at each time points the relative intensities of treated ones have been evaluated. $P$-value $<0.05$ was considered significant $\left({ }^{*}\right), P<0.01$ as highly significant $\left({ }^{*}\right)$ and $P<0.001$ as very highly significant $\left(^{(* *)}\right.$. (TIF $4078 \mathrm{~kb}$ )

\section{Abbreviations}

Bm_UGM: B. malayi UDP-Galactopyranose mutase protein; bmugm: B. malayi UDP-Galactopyranose mutase gene; siRNA: small interfering ribonucleic acids; UDP-Galf: UDP-Galactofuranose; UDP-Galp: UDP-Galactopyranose

\section{Acknowledgments}

We are thankful to Ms Shikha Mishra for her technical assistance in the maintenance of the B. malayi infection in the laboratory and Dr Mukesh Srivastava (Biostatistician, Clinical and Experimental Medicine division) for providing help in statistical analysis of data. The Council of Scientific and Industrial Research (CSIR) research fellowships to SM JG along and CSIR Network Project SPLenDID are gratefully acknowledged. This manuscript bears CDRI communication number 9363.

\section{Funding}

The financial supports in the form of research fellowships by Council of Scientific and Industrial Research (CSIR), New Delhi, India to SM JG along with financial assistance in the form of CSIR Network Project SPLenDID are gratefully acknowledged. The funders had no role in study design, data collection and analysis, decision to publish, or preparation of the manuscript.

\section{Availability of data and materials}

The datasets supporting the conclusions of this article are included within the article and its additional file.

\section{Authors' contributions}

Conceived and designed the experiments: SM and SMB. Performed the experiments: SM and JG Analyzed the data: SM. Contributed reagents/ materials/analysis tools: SMB. Wrote the paper: SM and SMB. All authors read and approved the final manuscript

\section{Competing interests}

The authors declare that they have no competing interests.

\section{Consent for publication}

Not applicable.

\section{Ethics approval}

Six-week-old male jirds (Meriones unquiculatus) were used in the current study. The animals were bred and maintained in the Animal House Facility of SSIR - Central Drug Research Institute (CDRI) Lucknow, India and fed on standard pellets and water ad libitum. The animals and animal handling procedures were prior approved by the Institute's Animal Ethics Committee (IAEC) constituted as per the guidelines of CPCSEA (Committee for the Purpose of Control and Supervision on Experiments on Animals), Government of India. The present study bears the approval no. IAEC/2011/ 120/Renew-3/Dated-14/08/2014. Animals were euthanized by overdosing of intraval sodium $(100 \mathrm{mg} / \mathrm{kg})$ and proper caution was taken to reduce the number of animals and their pain.

Received: 20 February 2016 Accepted: 4 January 2017

Published online: 19 January 2017

\section{References}

1. WHO. Lymphatic filariasis, Fact sheet No. 102. Geneva: World Health Organization; 2015. http://www.who.int/mediacentre/factsheets/fs102/en.

2. Wolstenholme AJ, Fairweather I, Prichard R, von Samson-Himmelstjerna G, Sangster NC. Drug resistance in veterinary helminths. Trends Parasitol. 2004; 20(10):469-76

3. Peltier P, Euzen R, Daniellou R, Nugier-Chauvin C, Ferrieres V. Recent knowledge and innovations related to hexofuranosides: structure, synthesis and applications. Carbohydr Res. 2008;343(12):1897-923.

4. Tefsen B, Ram AF, van Die I, Routier FH. Galactofuranose in eukaryotes: aspects of biosynthesis and functional impact. Glycobiology. 2012;22(4):456-69.
5. Latge JP. Galactofuranose containing molecules in Aspergillus fumigatus. Med Mycol. 2009:47(sup1):S104-9.

6. Beverley $\mathrm{SM}$, Owens $\mathrm{KL}$, Showalter M, Griffith $\mathrm{CL}$, Doering $\mathrm{TL}$, Jones VC, McNeil MR. Eukaryotic UDP-galactopyranose mutase (GLF gene) in microbial and metazoal pathogens. Eukaryot Cell. 2005;4(6):1147-54.

7. Kleczka B, Lamerz AC, van Zandbergen G, Wenzel A, Gerardy-Schahn R, Wiese M, Routier FH. Targeted gene deletion of Leishmania major UDPgalactopyranose mutase leads to attenuated virulence. J Biol Chem. 2007; 282(14):10498-505.

8. Schmalhorst PS, Krappmann S, Vervecken W, Rohde M, Müller M, Braus GH, et al. Contribution of galactofuranose to the virulence of the opportunistic pathogen Aspergillus fumigatus. Eukaryot Cell. 2008;7(8):1268-77.

9. Novelli JF, Chaudhary K, Canovas J, Benner JS, Madinger CL, Kelly P, et al. Characterization of the Caenorhabditis elegans UDP-galactopyranose mutase homolog glf-1 reveals an essential role for galactofuranose metabolism in nematode surface coat synthesis. Dev Biol. 2009;335(2):340-55.

10. Ashrafi K, Chang FY, Watts JL, Fraser AG, Kamath RS, Ahringer J, Ruvkun G. Genome-wide RNAi analysis of Caenorhabditis elegans fat regulatory genes. Nature. 2003;421(6920):268-72.

11. Kamath RS, Fraser AG, Dong Y, Poulin G, Durbin R, Gotta M, et al. Systematic functional analysis of the Caenorhabditis elegans genome using RNAi. Nature. 2003;421(6920):231-7.

12. Simmer F, Moorman C, van der Linden AM, Kuijk E, van den Berghe PV, Kamath RS, et al. Genome-wide RNAi of C. elegans using the hypersensitive rrf-3 strain reveals novel gene functions. PLoS Biol. 2003;1(1):E12.

13. Rual JF, Ceron J, Koreth J, Hao T, Nicot A-S, Hirozane-Kishikawa T, et al. Toward improving Caenorhabditis elegans phenome mapping with an ORFeome-based RNAi library. Genome Res. 2004;14(10b):2162-8.

14. Samuelson AV, Carr CE, Ruvkun G. Gene activities that mediate increased life span of C. elegans insulin-like signaling mutants. Gene Dev. 2007;21(22): 2976-94.

15. Latha AA, Narayanan R. UDP-galactopyranose mutase as a possible drug target for the human filarial parasite, Brugia malayi: an in silico evaluation. Int J Med Eng Inform. 2013;5(4):372-82.

16. McCall JW, Malone JB, Hyong-Sun A, Thompson PE. Mongolian jirds (Meriones unguiculatus) infected with Brugia pahangi by the intraperitoneal route: a rich source of developing larvae, adult filariae, and microfilariae. J Parasitol. 1973:59(3):436.

17. Singh PK, Kushwaha S, Mohd S, Pathak M, Misra-Bhattacharya S. In vitro gene silencing of independent phosphoglycerate mutase (iPGM) in the filarial parasite Brugia malayi. Infec Dis poverty. 2013;2(1):5.

18. Kushwaha S, Singh PK, Shahab M, Pathak M, Bhattacharya SM. In vitro silencing of Brugia malayi trehalose-6-phosphate phosphatase impairs embryogenesis and in vivo development of infective larvae in jirds. PLoS Negl Trop Dis. 2012;6(8):e1770.

19. Mukherjee M, Misra S, Chatterjee R. Development of in vitro screening system for assessment of antifilarial activity of compounds. Acta Trop. 1998; 70(3):251-5.

20. Misra S, Verma M, Mishra SK, Srivastava S, Lakshmi V, Misra-Bhattacharya S. Gedunin and photogedunin of Xylocarpus granatum possess antifilarial activity against human lymphatic filarial parasite Brugia malayi in experimental rodent host. Parasitol Res. 2011;109(5):1351-60.

21. Singh M, Singh PK, Misra-Bhattacharya S. RNAi mediated silencing of ATPase RNA helicase gene in adult filarial parasite Brugia malayi impairs in vitro microfilaria release and adult parasite viability. J Biotechnol. 2012; 157(3):351-8

22. Livak KJ, Schmittgen TD. Analysis of relative gene expression data using real-time quantitative PCR and the $2-\Delta \Delta C T$ method. Methods. 2001;25(4): 402-8.

23. Shahab M, Verma M, Pathak M, Mitra K, Misra-Bhattacharya S. Cloning, expression and characterization of UDP-NAcetylglucosamine enolpyruvyl transferase (MurA) from Wolbachia endosymbiont of human lymphatic filarial parasite Brugia malayi. PLoS One. 2014;9(6), e99884.

24. Hoerauf A, Pfarr K, Mand S, Debrah A, Specht S. Filariasis in Africa treatment challenges and prospects. Clin Microbiol Infect. 2011;17(7):977-85.

25. Lustigman S, Prichard RK, Gazzinelli A, Grant WN, Boatin BA, McCarthy JS, Basáñez MG. A research agenda for helminth diseases of humans: the problem of helminthiases. PLoS Negl Trop Dis. 2012;6(4), e1582.

26. Prichard RK, Basáñez M-G, Boatin BA, McCarthy JS, García HH, Yang G-J, et al. A research agenda for helminth diseases of humans: intervention for control and elimination. PLoS Negl Trop Dis. 2012;6(4), e1549. 
27. Britton C, Winter AD, Marks ND, Gu H, McNeilly TN, Gillan V, Devaney E. Application of small RNA technology for improved control of parasitic helminths. Vet Parasitol. 2015;212(1):47-53.

28. Hussein AS, Kichenin K, Selkirk ME. Suppression of secreted acetylcholinesterase expression in Nippostrongylus brasiliensis by RNA interference. Mol Biochem Parasitol. 2002;122(1):91-4.

29. Islam MK, Miyoshi T, Yamada M, Tsuji N. Pyrophosphatase of the roundworm Ascaris suum plays an essential role in the worm's molting and development. Infect Immun. 2005;73(4):1995-2004

30. Chen N, Xu M-J, Nisbet AJ, Huang C-Q, Lin R-Q, Yuan Z-G, et al. Ascaris suum: RNAi mediated silencing of enolase gene expression in infective larvae. Exp Parasitol. 2011;127(1):142-6.

31. Geldhof P, Murray L, Couthier A, Gilleard JS, McLauchlan G, Knox DP, Britton C. Testing the efficacy of RNA interference in Haemonchus contortus. Int J Parasitol. 2006:36(7):801-10.

32. Kotze AC, Bagnall NH. RNA interference in Haemonchus contortus: suppression of beta-tubulin gene expression in L3, L4 and adult worms in vitro. Mol Biochem Parasitol. 2006;145(1):101-10.

33. Samarasinghe $B$, Knox DP, Britton $C$. Factors affecting susceptibility to RNA interference in Haemonchus contortus and in vivo silencing of an $\mathrm{H} 11$ aminopeptidase gene. Int J Parasitol. 2011;41(1):51-9.

34. Pfarr $\mathrm{K}$, Heider $U$, Hoerauf A. RNAi mediated silencing of actin expression in adult Litomosoides sigmodontis is specific, persistent and results in a phenotype. Int J Parasitol. 2006;36(6):661-9.

35. Lustigman S, Zhang J, Liu J, Oksov Y, Hashmi S. RNA interference targeting cathepsin $L$ and Z-like cysteine proteases of Onchocerca volvulus confirmed their essential function during L3 molting. Mol Biochem Parasitol. 2004; 138(2):165-70

36. Ford L, Guiliano DB, Oksov Y, Debnath AK, Liu J, Williams SA, et al. Characterization of a novel filarial serine protease inhibitor, Ov-SPI-1, from Onchocerca volvulus, with potential multifunctional roles during development of the parasite. J Biol Chem. 2005;280(49):40845-56.

37. Issa Z, Grant W, Stasiuk S, Shoemaker C. Development of methods for RNA interference in the sheep gastrointestinal parasite, Trichostrongylus colubriformis. Int J Parasitol. 2005;35(9):935-40.

38. Visser A, Geldhof P, De Maere V, Knox D, Vercruysse J, Claerebout E. Efficacy and specificity of RNA interference in larval life-stages of Ostertagia ostertagi. Parasitology. 2006;133(Pt 6):777-83.

39. Song C, Gallup JM, Day TA, Bartholomay LC, Kimber MJ. Development of an in vivo RNAi protocol to investigate gene function in the filarial nematode, Brugia malayi. PLoS Pathog. 2010;6(12):e1001239.

40. Ford L, Zhang J, Liu J, Hashmi S, Fuhrman JA, Oksov Y, Lustigman S. Functional analysis of the cathepsin-like cysteine protease genes in adult Brugia malayi using RNA interference. PLoS Negl Trop Dis. 2009;3(2):e377.

41. Aboobaker AA, Blaxter ML. Use of RNA interference to investigate gene function in the human filarial nematode parasite Brugia malayi. Mol Biochem Parasitol. 2003;129(1):41-51.

42. Lustigman S, Melnikow E, Anand SB, Contreras A, Nandi V, Liu J, et al. Potential involvement of Brugia malayi cysteine proteases in the maintenance of the endosymbiotic relationship with Wolbachia. Int J Parasitol Drugs Drug Resist. 2014;4(3):267-77.

43. Elbashir SM, Lendeckel W, Tuschl T. RNA interference is mediated by 21 -and 22-nucleotide RNAs. Gen Dev. 2001;15(2):188-200.

44. Elbashir SM, Martinez J, Patkaniowska A, Lendeckel W, Tuschl T. Functional anatomy of siRNAs for mediating efficient RNAi in Drosophila melanogaster embryo lysate. The EMBO J. 2001;20(23):6877-88.

45. Elbashir SM, Harborth J, Weber K, Tuschl T. Analysis of gene function in somatic mammalian cells using small interfering RNAs. Methods. 2002;26(2): 199-213.

46. Holen T. Mechanisms of RNAi: mRNA cleavage fragments may indicate stalled RISC. J RNAi Gene Silencing. 2005;1(1):21.

47. Reynolds A, Anderson EM, Vermeulen A, Fedorov Y, Robinson K, Leake D, et al. Induction of the interferon response by siRNA is cell type-and duplex length-dependent. RNA. 2006;12(6):988-93.

48. Bantounas I, Phylactou L, Uney J. RNA interference and the use of small interfering RNA to study gene function in mammalian systems. J Mol Endocrinol. 2004;33(3):545-57.

49. Darby C, Chakraborti A, Politz SM, Daniels CC, Tan L, Drace K. Caenorhabditis elegans mutants resistant to attachment of Yersinia biofilms. Genetics. 2007; 176(1):221-30
50. Partridge FA, Tearle AW, Gravato-Nobre MJ, Schafer WR, Hodgkin J. The C. elegans glycosyltransferase BUS-8 has two distinct and essential roles in epidermal morphogenesis. Dev Biol. 2008;317(2):549-59.

51. Gravato-Nobre MJ, Nicholas HR, Nijland R, O'Rourke D, Whittington DE, Yook KJ, Hodgkin J. Multiple genes affect sensitivity of Caenorhabditis elegans to the bacterial pathogen Microbacterium nematophilum. Genetics. 2005;171(3): 1033-45.

52. Höflich J, Berninsone P, Göbel C, Gravato-Nobre MJ, Libby BJ, Darby C, et al. Loss of srf-3-encoded nucleotide sugar transporter activity in Caenorhabditis elegans alters surface antigenicity and prevents bacterial adherence. J Biol Chem. 2004:279(29):30440-8.

53. Yook K, Hodgkin J. Mos 1 mutagenesis reveals a diversity of mechanisms affecting response of Caenorhabditis elegans to the bacterial pathogen Microbacterium nematophilum. Genetics. 2007;175(2):681-97.

\section{Submit your next manuscript to BioMed Central and we will help you at every step:}

- We accept pre-submission inquiries

- Our selector tool helps you to find the most relevant journal

- We provide round the clock customer support

- Convenient online submission

- Thorough peer review

- Inclusion in PubMed and all major indexing services

- Maximum visibility for your research

Submit your manuscript at www biomedcentral.com/submit
C Biomed Central 